\title{
14
}

\section{Crowdfunding in Africa: Opportunities and Challenges}

\author{
Emmanuel James Chao, Priscilla Serwaah, \\ Prince Baah-Peprah, and Rotem Shneor
}

\section{Introduction}

The crowdfunding phenomenon in Africa is somewhat lagging other regions and is still at its infancy. Despite the relatively slow adoption of crowdfunding in Africa, it is often regarded as a mechanism with great potential for increasing access to finance for entrepreneurs in developing economies in general and Africa in particular (The World Bank Group 2015). According to the Cambridge Centre for Alternative Finance (hereafter- "CCAF"), African volumes in a variety of crowdfunding models reached US $\$ 182$ million in 2016, growing $118 \%$ from US $\$ 83$ million in 2015 (Ziegler et al. 2018). From a regional perspective,

E. J. Chao (殴

Mzumbe University, Mzumbe, Tanzania e-mail: ejchao@mzumbe.ac.tz

P. Serwaah • P. Baah-Peprah • R. Shneor School of Business and Law, University of Agder, Kristiansand, Norway e-mail: priscilla.serwaah@uia.no; prince.baah-peprah@uia.no;

rotem.shneor@uia.no 
whereas $41 \%$ of these volumes have been recorded in West Africa, 28\% have been recorded in Southern Africa, 24\% in Eastern Africa, and the remaining 7\% in North and Central Africa (ibid.).

Despite representing the smallest global region in terms of volumes, Africa exhibits one of the greatest potentials for crowdfunding growth. This potential is based on Africa's global leading position in terms of adopting digital finance and mobile money, the relative low penetration of traditional financial institutions, as well as crowdfunding's cultural fit with traditional funding practices. Evidence shows that digital financial solutions have been expanding access and reach to consumers, especially for the unbanked and under-banked, while significantly lowering costs of such services and making it possible to serve the base of the pyramid in a more profitable way (Rowan et al. 2018). Furthermore, mobile money became an important component in Africa's financial services landscape, as driven by more than 140 mobile money service firms catering to one in every ten African adults (Chironga et al. 2017).

At the same time, low penetration levels of traditional financial institutions, such as banks and funds, are prevalent in many African economies (KPMG 2015). This situation leads to a systematic discrimination of micro and small enterprises in terms of access to finance, as well as often insurmountable guarantees that are required for such financing when access to finance is at least formally available. Efforts have been made to fill this gap through financial solutions provided by microcredit agencies and community institutions (George et al. 2016). However, the extent to which such interventions provide an efficient and sustainable solution remains questionable. In this context, several studies compare crowdfunding to microfinance while suggesting that the advantages of the former can compensate for the inefficiencies in the latter (Wolf 2017; Oruezabala and Peter 2016).

In terms of cultural fit, some of the limited research into crowdfunding in Africa argues that modern crowdfunding can function well in supplying funding for African entrepreneurs as it represents a technological solution for "centuries-old and culturally-rooted sub-Saharan practices of individuals helping each other through communal reciprocity" (Wolf 2017). Some also argue that it can be viewed as a conceptual broadening of the participatory financing system familiar to locals from microfinance 
institutions (Oruezabala and Peter 2016). Furthermore, the potential for crowdfunding is also linked to contributions through diaspora philanthropy, where social capital embedded in African diaspora connections may translate into diaspora members funding of entrepreneurs in their countries of origin (Flanigan 2017). Here, while African entrepreneurs exhibit limited knowledge of crowdfunding, they also express interest in using it once familiarized with the concept, as shown by a pioneering study made in Rwanda (Berndt and Mbassana 2016).

Overall, the conditions presented above seem to suggest great promise for crowdfunding in answering market needs that are insufficiently met by existing institutions, while simultaneously supporting development, growth, and entrepreneurship. In the current chapter we explore the current state of crowdfunding research and practice in Africa, while highlighting some of the challenges and gaps for further exploration.

\section{The Current State of Crowdfunding in Africa}

In reviewing the current state of the crowdfunding industry in Africa, we mostly report findings from the CCAF second annual Middle East and Africa bench-mark report (Ziegler et al. 2018). And, hence, unless otherwise noted, all facts and figures presented in this subsection are referring to findings from the above-named source.

Unlike other regions, where funding is locally driven by indigenous investors and platforms, crowdfunding in Africa has extensively been dominated by backers from outside of Africa. In 2016, African crowdfunding volumes reached $\$ 181.27$ million, while growing $118 \%$ from 2015. However, a substantial part of this amount, capturing $88 \%$ of 2016 volumes and $89 \%$ of the 2015 volumes, was raised through foreignbased platforms headquartered in Europe and the United States. The growth curve and the dominance of foreign funds signal Africa's unexploited crowdfunding opportunities and the embryonic status of crowdfunding as a financing vehicle in Africa. These indicators may suggest several implications worth highlighting. First, there is a high possibility for the continent to continue to experience exponential growth. Second, a growing share of activities may emerge from within Africa as local 
platforms sprout, the populace gets better educated about and better familiarized with crowdfunding, and as regulatory institutions build legal frameworks that are more conducive and enabling of a crowdfunding ecosystem. Such developments are likely to increase indigenous backers' and investors' appetite towards crowdfunding local projects.

The African continent includes multiple regional and national markets with diverse development levels, institutional environments, and geographical conditions. Such diversity is also evident when examining the development of crowdfunding in various regions of the continent. Here, in terms of size, between 2013 and 2016, the East African region has emerged as a consistent market leader with an average annual market share of $38 \%$. West Africa comes second with 34\%, followed by the South African region with $17 \%$. Central and North Africa are behind with $7 \%$ and $4 \%$ respectively. While some decline was registered in East and Central Africa in recent years, dramatic growth has been recorded in Southern Africa (824\% in 2015 and 116\% in 2016) and Western Africa (150\% in 2016), which are associated with market development in South Africa and Nigeria respectively. Strong growth was also observed in North Africa growing 80\% on average between 2013 and 2016, with most activities in Egypt.

At the national level, Kenya and Uganda dominate the Eastern African region. Nigeria and Cote D'Ivoire account for the major share of the Western African region. South Africa, Rwanda, and Egypt solely dominate the Southern, Central, and the Northern African regions respectively. On a continental basis, Nigeria, South Africa, and Kenya dominate Africa's crowdfunding industry overall. These three countries jointly account for $74-82 \%$ of annual African crowdfunding market volumes between 2013 and 2016.

When examining African crowdfunding by model, and like other global regions, evidence shows that a large proportion of crowdfunding volume is associated with investment models, which accounted for $79 \%$ of total volumes in 2015 and 63\% in 2016. When splitting these volumes further among the various investment models, lending-based models jointly account for the largest share of investment-crowdfunding volumes, capturing 90\% of such volumes in 2015 and $56 \%$ in 2016. These percentages correspond to volumes equal to \$59 million in 2015 
and $\$ 63$ million in 2016 . This development is mostly evident with respect to peer-to-peer business lending that grew $46 \%$ between 2015 and 2016 , while crowd-based pro-social microlending remained stable at $\$ 34$ million in both 2015 and 2016. Nevertheless, 2016 has seen the introduction of additional crowdfunding investment models in the continent. Here, equity, real estate, and profit-sharing models grew from $\$ 6.39$ million in 2015 to $\$ 51.31$ million in 2016, jointly representing an impressive $701 \%$ growth. Overall, the emergence of these models jointly represents $28 \%$ of total volumes raised in 2016, which explains the shrinking share of crowdlending out of investment model volumes, while the actual amount has increased.

At the same period, non-investment models of crowdfunding accounted for $21 \%$ of total volumes raised in 2015 and $37 \%$ of volumes in 2016. Here, reward-based crowdfunding experienced a modest increase from $\$ 3.17$ million in 2015 to $\$ 4.17$ million in 2016 , while accounting for $2.3 \%$ of total volumes raised in 2016 . Donation-based crowdfunding, on the other hand, exhibits more substantial volumes and growth while mostly relying on funders based outside of Africa. Under this model, $\$ 14.26$ million were raised in 2015 and $\$ 63.11$ million were raised in 2016, growing 342\% between 2015 and 2016. This implies that donation crowdfunding is the single largest model of crowdfunding in the continent, representing 35\% of total volumes raised in Africa during 2016. This stands at a stark contrast to all other regions in the world, where peer-to-peer lending models dominate.

While not yet substantiated in empirical research, one may suggest several explanations for the prominence of donation crowdfunding in the African crowdfunding context. First, one can argue that Africa is just following market development observed elsewhere, where initial crowdfunding activities were associated with non-investment types of crowdfunding that later paved the way towards the proliferation of investment-crowdfunding platforms (Bruton et al. 2015). Indeed, these dynamics have been observed in many countries in Europe, Asia, and the Americas. Second, and closely linked to the previous explanation, is the concern with risk and development of trust. In this sense, non-investmentcrowdfunding engagements represent lower risk, involve modest sums, and are characterized by fewer regulatory compliance barriers than 
investment crowdfunding (Belleflamme and Lambert 2016; Ziegler et al. 2019). As such, non-investment crowdfunding becomes easier to implement and experiment with. Once individuals accumulate positive experiences with these models, they may develop greater willingness to gradually engage in activities that may be considered riskier, involve higher sums, and may carry greater regulatory implications (e.g. investor protection).

As the status of crowdfunding practice is now established, we now turn to examining the status of research on crowdfunding in African contexts while presenting key findings emerging from such academic work.

\section{Emerging Insights from Crowdfunding Research in Africa}

Research into crowdfunding in Africa is limited and represents early stages of market development, with most related studies being more conceptual in nature. Here, according to Wolf (2017), the crowdfunding phenomenon is congruent with traditional communal reciprocity culture of sub-Saharan African individuals. This view is also shared by Berndt (2016), who suggests that crowdfunding is a modern form of credit associations in the African context, where individuals invest in the businesses of others. Interestingly, the tradition of credit associations and other forms of microfinancing (delivered in diverse formats) have existed in many African cultures for decades. Credit associations work on the principle of communal reciprocity, where individuals usually contribute money periodically into a communal fund and the collected amount is either shared among the community members or invested on their behalf (ibid.). Notable examples of these credit associations include Susu in Ghana, Mabati in Kenya, Ekub in Ethiopia, Tontine in Mali, and Stokvels in South Africa (Coetzee 2013). Regardless of the form, these schemes thrive on small-scale financing to support group saving methods, and often involved communities are embedded with a culture of mutual supporting for business ideas.

Several studies attempt to compare crowdfunding to microfinance, with authors proposing that the advantages of the former can compensate 
for the inefficiencies in the latter (Wolf 2017; Oruezabala and Peter 2016). Here, based on a sample of 50 Gabonese small businesses, Oruezabala and Peter (2016) note that $78 \%$ of these SMEs derived their funding from personal funds, family, and credit associations. Thus, most of these small businesses are excluded from microfinancing, possibly due to their inability to meet certain requirements. Indeed, the researchers argue that some Microfinance Institutions are moving away from their social mission, a development that opens opportunities for crowdfunding platforms and makes crowdfunding an attractive alternative for small businesses.

Wolf (2017) suggests that the over-reliance of microfinance on subsidies makes it unsustainable thereby limiting its success and impact. Moreover, there have been calls for microfinance to focus not only on poverty reduction but also on social emancipation through creativity (de Haan and Lakwo 2010). In contrast, crowdfunding platforms are known avenues for creative and innovative ventures (Wolf 2017). Thus, although crowdfunding might draw some inspiration from microfinancing (Munyanyi and Mapfumo 2018), it can promote co-creation of innovation between entrepreneurs and funders (Wolf 2017) while strengthening the overall entrepreneurial financing dynamics which already exist in the microfinance industry (Oruezabala and Peter 2016). Accordingly, in their proposed model for crowdfunding penetration and success in Africa, Oruezabala and Peter (ibid.) present crowdfunding platforms as a source of new resources, rather as a new way to tap into old resources.

To these considerations, Flanigan (2017) introduces an additional important consideration by examining how crowdfunding could contribute towards enhancing diaspora philanthropy. For this purpose, she defined diaspora philanthropy as "money, goods, volunteer labor, knowledge and skills, and other assets donated for the social benefit of a community broader than ones' family members, in a country or region where there is a population with whom the donor(s) have ancestral ties" (ibid., p. 498). Here, Flanigan notes that an integration of the literature on the two phenomena shows that crowdfunding technologies could enhance the delivery of diaspora philanthropy-where diaspora philanthropy is seen as a subset of remittance flows into countries. 
In the same spirit, online philanthropy may be viewed as the giving of financial and social capital for promoting human welfare through online platforms (Munyanyi and Mapfumo 2018). Hence, through crowdfunding, African migrants can continue supporting entrepreneurial activities by helping family members and friends in their countries of origin via the mediation of crowdfunding platforms. Again, this may be in tandem with remittances which serves as an important source of incoming capital in many African countries. Indeed, remittances sent by African migrants reached nearly $\$ 40$ billion in 2010 , an amount equivalent to $2.6 \%$ of Africa's gross domestic product (Mohapatra and Dilip 2011). As noted by Flanigan (2017), strategically capitalizing on the shared characteristics and complementary strengths of crowdfunding and diaspora philanthropy can help diaspora generated 'philanthropic crowdfunding' thrive.

Furthermore, diaspora members offer networks and knowledge that could help offset crowdfunding's vulnerabilities. Indeed, earlier research shows that diaspora networks have significant impact on cross-border investment (Leblang 2010). And that diaspora investments in countries of origin are affected by perceived ethnic advantage (over other investors) and altruistic tendencies, while perceptions of business impediments do not affect such investments (Gillespie et al. 1999). Bringing such insights into the context of crowdfunding, platforms may reduce informational and technical barriers for such investment opportunities and may enhance their likelihood by tapping into diaspora members' sense of ethnic advantage and altruistic orientation towards opportunities in their countries of origin. The latter reflecting beliefs that investors should invest in one's country of origin and not just send donations there (ibid.). One example for such initiative is the French-based LelapaFund platform, which is dedicated to facilitating investments in Africa by tapping onto African diasporas, which, according to one of its co-founders, perceive fewer barriers to such investments while normalizing risk associated with African venturing (Mulligan 2015).

Other authors have explored the factors influencing the plausibility of crowdfunding in Africa. More specifically, Munyanyi and Mapfumo (2018), focusing on Zimbabwe, identified four factors that influence the plausibility of crowdfunding, including strong and active social network, easy and reliable payment system, a passionate audience, and a funding 
gap. In this context, the identification of crowdfunding success drivers in Africa and how they can be directed towards economic development in the region are extremely important for both entrepreneurs and funders. A good example of such approach can be found in suggestions that crowdfunding may be adapted to solving regional issues such as power shortages, which are usually experienced in most parts of Africa, and by addressing a concrete need affecting people's lives, which will make crowdfunding more attractive for those who live in affected areas (Berndt 2016).

\section{Challenges for the Development of Crowdfunding in Africa}

Whereas crowdfunding is considered to present great opportunities towards enhancing access to finance, as well as supporting entrepreneurship, innovation, and development in Africa, it is also important to consider some challenges that may hinder crowdfunding adoption and growth in the continent. This is especially important when taking into considerations that the main vehicles for crowdfunding market development, namely crowdfunding platforms, are mostly entrepreneurial ventures themselves. And while entrepreneurs deal with adversity regardless of context, some challenges reign prominent in African contexts in general (e.g. Alon and Shneor 2017; Belwal and Singh 2008) and the African crowdfunding context in particular.

\section{Regulation}

In this context, researchers particularly emphasize that regulatory factors matter (Berndt 2016; Flanigan 2017). This assertion is supported by Munyanyi and Mapfumo (2018) who argue that, despite the viability of crowdfunding in Zimbabwe, there is a lot to be done to set up an enabling regulatory framework in the country. Overall, the health and strength of the SME sector in Africa is often viewed as a policy priority in most countries across the continent. Accordingly, African governments may 
address crowdfunding regulation as an enabler of domestic innovation and entrepreneurship. One path for such development may be facilitated by learning from the experiences of other countries elsewhere around the world. In this context, earlier research in Europe indeed showed that the more adequate national regulation is perceived to be by platforms operating in the same national market, the higher the overall crowdfunding volumes per capita in the same market (Ziegler et al. 2019).

Thus far, there remains "no bespoke, tailor-made alternative finance regulation regime that has been enacted in Africa as has been the case in other more established markets" (Ziegler et al. 2018, p. 22). And, in the absence of crowdfunding-specific regulation, generic financial services regulation applies to firms seeking to provide services falling within the scope of activities covered in existing laws. Nevertheless, several regulatory initiatives to support financial innovation more generally have been adopted by various African government agencies. These include, but are not limited to, various steps taken towards establishing regulatory sandbox processes for financial technology companies in Kenya, Mauritius, Mozambique, Rwanda, South Africa, and Uganda (Ziegler et al. 2018). In addition, the African Crowdfunding Association was established in 2015 as an industry organization dedicated to lobbying in favour of crowdfunding legislation creation and reforms, increasing public awareness of crowdfunding, and ensuring industry practices that protect investors and democratize access to capital (African Crowdfunding Association 2019).

\section{Information Technology Infrastructure}

Since online forms of crowdfunding heavily depend on access to social media and social networking sites, as well as web-based platforms, internet access is paramount to its successful dissemination and uptake. Here, an important challenge for the development of the industry in Africa relates to internet infrastructure and the relative low internet penetration in many regions across the continent. As a whole, internet penetration rate in Africa stood at just 37.3\% in May 2019 in comparison to 60.8\% in the rest of the world (Miniwatts Marketing Group 2019). Here, again, 
regional and national variations do exist, and while some countries report relatively high penetration levels such as $83 \%$ in Kenya and $80.1 \%$ in Liberia, others exhibit much lower rates such as $1.3 \%$ in Eritrea and $4.1 \%$ in Niger (ibid.). Such conditions limit the ability of African fundraisers to capitalize on the value of network externalities in crowdfunding (Wolf 2017). To overcome such challenges, crowdfunding platforms operating in Africa have leveraged mobile technology while using innovative ways to create and promote projects via SMS, popular mobile apps (e.g. WhatsApp, Messenger, Viber), and use of mobile money to fund projects (Boum 2016).

\section{Social Trust}

Furthermore, from a social-normative perspective, African countries are often found to be characterized by a relative low level of social trust (Delhey and Newton 2005). Social trust was defined as "the belief that others will not deliberately or knowingly do us harm, if they can avoid it, and will look after our interests, if this is possible" (ibid., p. 311). While this may seem at odds with traditional crowdfunding practices in Africa, it is explained by the distinction between trust towards in-group members versus strangers. Africans may exhibit trust towards familiar in-group members, while exhibiting lower levels of trust towards strangers outside their immediate circle of acquaintances (Posel and Hinks 2012) than other societies. However, both trust between strangers and trust towards online transaction are required in order to facilitate a thriving crowdfunding market (Kshetri 2015).

Research from other contexts of online transactions shows that satisfactory online customer experience enhances trust in e-retailing/online shopping (Rose et al. 2012) and in e-banking/online banking (Ghane et al. 2011). Taken together, these insights may suggest that trust can also be created with experience, and that adoption may be enhanced by creating opportunities for crowdfunding experience with low entry thresholds. Moreover, the transparency involved in crowdfunding transactions can serve as a trust facilitating mechanism (Spanos 2018). Here, information about delivery and repayment of loans, as well as non-delivery or 
non-payment on loans, will be publicly available and deter fundraisers from shirking such responsibilities for avoiding a damage to their reputation and self-image. Indeed, research shows that concerns about disclosure, visible failure, and projecting desperation hinder entrepreneurs from using crowdfunding (Gleasure 2015), and by extension may help curtail related moral hazards. In addition to the above, the transparent digital recording of transactions can also help in limiting opportunities for corruption in the financial sector, which represents a concern in various African countries (Hanlon 2002; Demetriades and Fielding 2012).

Finally, as platform survival and growth depend on positive user experiences and successful campaigning, most platforms engage in careful campaign filtration, validation, and selection processes. This is evident in platform onboarding rates, which reflect the percentage of campaigns published out of total campaigns requesting to be published on a given platform. Here, while onboarding rates are not yet available for African platforms, European platforms report average onboarding rates of $49 \%$ in reward crowdfunding, $74 \%$ in donation crowdfunding, $17-22 \%$ in leading crowdlending models, and 6\% in equity crowdfunding (Ziegler et al. 2019). In this sense, platforms serve as risk-reducing players in comparison to independent and unverified fundraising initiatives that do not go through the scrutiny of platform validation procedures (e.g. fundraiser identity verifications, background checks).

\section{Early Days of African Crowdfunding: Hybrid Forms of Crowdfunding}

As mentioned earlier, African crowdfunding for Africans and by Africans remains at a very early stage. Accordingly, fundraisers in this sphere attempt to tap into crowdfunding's promises of improved access to finance and enhanced transparency, while manoeuvring between existing barriers to adoption at both social and institutional levels. Such efforts can be characterized as hybrid forms of crowdfunding implying combinations of multiple channels for fundraising in addition to crowdfunding 
platforms. In this section, we present several illustrative examples of such hybrid forms from East African crowdfunding campaigns.

First, a donation campaign created for a Tanzanian member of parliament, who got shot and was severely injured, sought to raise funds for his medical treatments. The campaign was created on the US-based global platform Gofundme by a group of Tanzanian diaspora members in the United States (Kolumbia 2017). However, in parallel, locals in Tanzania used M-Pesa mobile money to support the same campaign where the money was being paid directly to the account of the beneficiary. The local campaign was steered primarily through Word of Mouth. Here, even though most of middle-class Tanzanian citizens had the capacity to make their contribution via the Gofundme platform, they preferred sending their contribution using mobile money and direct bank account transfers. As a result, most online contributors were members of the diaspora.

Second, a different donation campaign was created to raise fund for the development of the Fishmate platform. This platform aims to serve the fishing and aqua-culture industry as a channel for information aggregation and dissemination, as well as a marketplace linking demand and suppliers among fishing communities in Kenya. The campaign was created on the global Dutch-based platform Onepercentclub by the entrepreneur-Mukeli Matai (Raymond 2015). Here, again, support from foreign and diaspora members was collected via the platform, but in addition Mutai needed to build a group of individuals who would form the base of her campaign in Kenya. This group, however, was either unable or reluctant to contribute money through the platform. In response, Mutai formed an offline fundraising campaign effort known locally in its traditional name- "Harambee". Under this effort, a "treasurer" was appointed to collect money from contributors via the M-Pesa mobile payment system or in cash. This treasurer then made a single contribution to the Onepercentclub platform, which then transferred funds to Mutai's bank account. Overall, Fishmate raised $€ 2678$ from about 20 family members in Kenya, a sum which was later matched with $€ 6000$ from the Cheetah Fund. Here, the matching fund scheme presented is an important incentive for her network to contribute online via the platform and not directly. 
Third, in one of the first reward campaigns launched through a new platform being developed in Tanzania under the Dar Technology and Business Incubator, it was reported that individuals collected money from peers offline and then transferred the collected sum to the intended recipient. A major challenge from this method as highlighted by the platform owners is the difficulty in identifying those who contributed through offline groups because it is only possible to track the one who transferred the funds. As money laundering is a concern in most of the countries, it is important to establish the identity of contributors for complying with legal and ethical practices in fundraising. Here, while the platform does request detailed information from contributors of relatively large sums, it remains a challenge to establish the accuracy and trustworthiness of such information.

Overall, the above examples indicate that crowdfunding uptake in Africa requires overcoming challenges associated with trust and technical concerns at early stages of crowdfunding engagement. The cases presented above suggest that campaigners complement campaigns posted in online platforms with traditional or technical payment systems Africans are already well familiar with. Specifically, combinations of online and offline efforts seem to support fundraising activities by tapping into different groups of prospective contributors. Such approach has received support in earlier studies showing that offline activities play an important role in sustaining online communities (Lin 2007).

Indeed, initial steps towards understanding the role of offline activities in crowdfunding have shown several interesting findings in other contexts. Here, a study of civic crowdfunding (when citizens, in collaboration with government, fund projects providing a community service) concluded that integrating online and offline approaches are essential for such campaigns' success (Stiver et al. 2014). And, a different study on crowdlending in the United States showed that when borrowers are registered in same state as the borrowing group leader (used as proxy for likelihood of offline interactions) crowd loans get more bids from prospective lenders but show no effect on the total amount raised (Kuwabara et al. 2017). 


\section{Conclusion}

In this chapter, the current state of crowdfunding research and practice in Africa has been outlined while highlighting some of the opportunities and challenges associated with them. Overall, we show that African crowdfunding is at its infancy. However, the extent to which crowdfunding may deliver on its promises of improved access to finance and enablement of growth remains to be substantiated empirically as the market grows and the industry matures.

Here, on the one hand, conditions of growing popularity of digital and mobile finance, low penetration of traditional financial institutions, and a long cultural heritage of communal mutual support may enhance crowdfunding uptake. On the other hand, conditions of unclear regulation, relatively low levels of internet access, and societies characterized by low social trust may all hinder crowdfunding uptake. Hence, for wider public adoption of crowdfunding, stakeholders interested in such development may need to engage in relevant policy development, implementation of technological solutions suitable for available ICT and financial infrastructure, raising public awareness through education, reducing user entry barriers, and creating low-risk or risk-free incentives for trial. Such actions can support the shift away from donation collection to investment fundraising, and from reliance on foreign investors towards enabling local micro-investors to build up their own capital base.

\section{Implications for Future Research}

Our review clearly shows that research on crowdfunding in the African context remains limited and conceptual. This implies that opportunities for future research are abundant and especially when considering empirical work that can test and challenge insights and findings from elsewhere around the world. Specifically, future research should focus on investigating crowdfunding adoption and its implication for development in Africa. Such efforts will enhance the understanding of how and to what extent does crowdfunding help in unlocking the potential of access to finance and investment opportunities for wider financial inclusiveness, 
business development, and job creation in Africa. Studies on crowdfunding adoption may explore the applicability of existing theoretical frameworks such as the Technology Acceptance Model (Venkatesh and Davis 2000) and the Theory of Planned Behaviour (Ajzen 1991), as well as highlight needs for their modification in the new realities of digital and mobile finance in development contexts. Studies examining the impact of crowdfunding can help us measure and capture the extent to which crowdfunding contributes to venture creation, survival, and growth, as well as the extent to which crowdfunding enables greater inclusivity and access to finance for groups that traditionally struggle with it such as women (Carter and Rosa 1998; Coleman 2000) and minorities (Ram et al. 2003).

Furthermore, the African context itself may represent a particularly conducive environment to study several important issues. First, research should identify and explore the effectivity of mechanisms and strategies for establishing trust in crowdfunding in societies characterized by low social trust. Second, research can also examine complementarities of offline and online dimensions of crowdfunding in environments characterized by limited ICT infrastructure and e-readiness. Third, research can examine the role played by diaspora in African crowdfunding campaign success in general, as well as facilitators of trust for African crowdfunding campaigns particularly vis-à-vis other international supporters.

\section{Implications for Practice}

Our review also shows that the African crowdfunding industry is at its infancy. As a new emergent sector that aims to solve market gaps by both extending and supplementing existing fundraising channels, certain critical elements need to be developed for supporting such efforts. First, regulators should engage with domestic and international industry players, as well as peers in other countries in reviewing and amending legal frameworks towards accommodating a good balance between user and investor protection while enabling the industry's responsible and sustainable growth. In addition, government bodies in collaboration with educational institutions may engage in developing training programmes and 
dissemination of public information about the risks and benefits of using crowdfunding for fundraising and investment purposes for both individuals and organizations.

In parallel, platforms aiming to establish themselves in African markets need to invest their resources into developing technological solutions that fit development realities and infrastructure conditions in Africa (e.g. integration of mobile payment, social media, and instant messaging functionalities), implementing relevant filtration and validation procedures for quality assurance and avoidance of fraud (e.g. creative solutions for identity verification and documentation), as well as introducing incentive mechanisms to encourage trial by prospective users while reducing entry barriers and risks associated with such trial (e.g. internal insurance funds, gradual increasing sums for fundraising based on historical performance of users).

\section{References}

African Crowdfunding Association. (2019). African Crowdfunding Association: Moving Africa Forward [Online]. Cape Town, RSA: African Crowdfunding Association. Retrieved June 10, 2019, from https://africancrowd.org/.

Ajzen, I. (1991). The Theory of Planned Behavior. Organizational Behavior and Human Decision Process, 50(2), 179-211.

Alon, I., \& Shneor, R. (2017). More Than Makeup: How Atsoko Overcame the Challenges of Entrepreneurship in Tanzania. Global Business and Organizational Excellence, 36(6), 25-33.

Belleflamme, P., \& Lambert, T. (2016). An Industrial Organization Framework to Understand the Strategies of Crowdfunding Platforms. In J. Méric, I. Maque, \& J. Brabet (Eds.), International Perspectives on Crowdfunding: Positive, Normative, and Critical Theory. Bingley, UK: Emerald Group Publishing Limited.

Belwal, R., \& Singh, G. (2008). Entrepreneurship and SMEs in Ethiopia:

Evaluating the Role, Prospects and Problems Faced by Women in This Emergent Sector. Gender in Management: An International Journal, 23(2), 120-136.

Berndt, A. (2016). Crowdfunding in the African Context: A New Way to Fund Ventures. In L. Achtenhagen \& E. Brundin (Eds.), Entrepreneurship and SME 
Management Across Africa: Context, Challenges, Cases. Singapore: Springer Singapore.

Berndt, A., \& Mbassana, M. (2016). Crowdfunding: The Beliefs of Rwandan Entrepreneurs. East Africa Research Papers in Business, Entrepreneurship and Management. Jönköping, Sweden: Jönköping University, Jönköping International Business School.

Boum, E. (2016). Crowdfunding in Africa: Fundraising Goes Digital in Africa The Emergence of Africa-Based Crowdfunding Platforms. Retrieved April 27, 2019, from http://afrikstart.com/report/wp-content/uploads/2016/09/ Afrikstart-Crowdfunding-In-Africa-Report.pdf.

Bruton, G., Khavul, S., Siegel, D., et al. (2015). New Financial Alternatives in Seeding Entrepreneurship: Microfinance, Crowdfunding, and Peer-to-Peer Innovations. Entrepreneurship Theory and Practice, 39(1), 9-26.

Carter, S., \& Rosa, P. (1998). The Financing of Male- and Female-Owned Businesses. Entrepreneurship \& Regional Development, 10(3), 225-242.

Chironga, M., De Grandis, H., \& Zouaoui, Y. (2017). Mobile Financial Services in Africa: Winning the Battle for the Customer. Retrieved from https://www. mckinsey.com/industries/financial-services/our-insights/mobile-financialservices-in-africa-winning-the-battle-for-the-customer.

Coetzee, J. (2013). Africa's Crowdfunding Context: Starting up Startups the African Way. Retrieved April 23, 2019, from https://ventureburn. $\mathrm{com} / 2013 / 07 /$ africas-crowdfunding-context-starting-up-startups-theafrican-way/.

Coleman, S. (2000). Access to Capital and Terms of Credit: A Comparison of Men- and Women-Owned Small Businesses. Journal of Small Business Management, 38(3), 37-52.

de Haan, L., \& Lakwo, A. (2010). Rethinking the Impact of Microfinance in Africa: 'Business Change' or Social Emancipation. The European Journal of Development Research, 22(4), 529-545.

Delhey, J., \& Newton, K. (2005). Predicting Cross-National Levels of Social Trust: Global Pattern or Nordic Exceptionalism? European Sociological Review, 21(4), 311-327.

Demetriades, P., \& Fielding, D. (2012). Information, Institutions, and Banking Sector Development in West Africa. Economic Inquiry, 50(3), 739-753.

Flanigan, S. T. (2017). Crowdfunding and Diaspora Philanthropy: An Integration of the Literature and Major Concepts. VOLUNTAS: International Journal of Voluntary and Nonprofit Organizations, 28(2), 492-509. 
George, G., Kotha, R., Parikh, P., et al. (2016). Social Structure, Reasonable Gain, and Entrepreneurship in Africa. Strategic Management Journal, 37(6), $1118-1131$.

Ghane, S., Fathian, M., \& Gholamian, M. R. (2011). Full Relationship Among e-Satisfaction, e-Trust, e-Service Quality, and e-Loyalty: The Case of Iran e-Banking. Journal of Theoretical and Applied Information Technology, 33(1), 1-6.

Gillespie, K., Riddle, L., Sayre, E., et al. (1999). Diaspora Interest in Homeland Investment. Journal of International Business Studies, 30(3), 623-634.

Gleasure, R. (2015). Resistance to Crowdfunding Among Entrepreneurs: An Impression Management Perspective. The Journal of Strategic Information Systems, 24(4), 219-233.

Hanlon, J. (2002). Bank Corruption Becomes Site of Struggle in Mozambique. Review of African Political Economy, 29(91), 53-72.

Kolumbia, L. (2017). Sh14m Raised Through Online Campaign for Lissu's Treatment in the Past Five Days. Retrieved January 14, 2020, from https:// www.thecitizen.co.tz/News/1840340-4110142-4f4pplz/index.html.

KPMG. (2015). Sector Report: Banking in Africa 2015. Johannesburg, SA: KPMG.

Kshetri, N. (2015). Success of Crowd-Based Online Technology in Fundraising: An Institutional Perspective. Journal of International Management, 21(2), 100-116.

Kuwabara, K., Anthony, D., \& Horne, C. (2017). In the Shade of a Forest Status, Reputation, and Ambiguity in an Online Microcredit Market. Social Science Research, 64, 96-118.

Leblang, D. (2010). Familiarity Breeds Investment: Diaspora Networks and International Investment. American Political Science Review, 104(3), 584-600. Lin, H. F. (2007). The Role of Online and Offline Features in Sustaining Virtual Communities: An Empirical Study. Internet Research, 17(2), 119-138.

Miniwatts Marketing Group. (2019). Internet World Stats [Online]. Miniwatts Marketing Group. Retrieved June 5, 2019, from https://www.internetworldstats.com/stats1.htm.

Mohapatra, S., \& Dilip, R. (2011). Migrant Remittances in Africa: An Overview. In S. Mohapatra \& R. Dilip (Eds.), Remittance Markets in Africa. Washington, DC: The World Bank.

Mulligan, G. (2015). Africa Discovers the Power of Crowdfunding. Retrieved January 14, 2020, from https://www.bbc.com/news/business-33100535. 
Munyanyi, W., \& Mapfumo, A. (2018). Factors Influencing Crowdfunding Plausibility in Post Hyperinflationary Zimbabwe. International Journal of Contemporary Applied Researches, 5(10), 99-111.

Oruezabala, G., \& Peter, S. G. (2016). Equity Crowdfunding in Africa: How Can Investment Micro-Behaviors Make the Crowdfunding Macro-System Work? In J. Méric, I. Maque, \& J. Brabet (Eds.), International Perspectives on Crowdfunding. Emerald Group Publishing Limited.

Posel, D., \& Hinks, T. (2012). Trusting Neighbours or Strangers in a Racially Divided Society: Insights from Survey Data in South Africa. Journal of African Economies, 22(1), 136-162.

Ram, M., Smallbone, D., Deakins, D., et al. (2003). Banking on 'Break-Out':

Finance and the Development of Ethnic Minority Businesses. Journal of Ethnic and Migration Studies, 29(4), 663-681.

Raymond, S. (2015). Six Things You Need to Know About Crowdfunding in Developing Countries. World Bank Blogs [Online]. Retrieved December 16, 2019, from http://blogs.worldbank.org/psd/six-things-you-need-knowabout-crowdfunding-developing-countries.

Rose, S., Clark, M., Samouel, P., et al. (2012). Online Customer Experience in e-Retailing: An Empirical Model of Antecedents and Outcomes. Journal of Retailing, 88(2), 308-322.

Rowan, P., Garvey, K., Zhang, B., et al. (2018). FinTech in Uganda: Implications for Regulation. Cambridge, UK: Cambridge Center for Alternative Finance. Spanos, L. (2018). Complementarity and Interconnection Between CSR and Crowdfunding: A Case Study in Greece. In G. Grigore, A. Stancu, \& D. McQueen (Eds.), Corporate Responsibility and Digital Communities: An International Perspective Towards Sustainability. Cham: Springer International Publishing.

Stiver, A., Barroca, L., Minocha, S., et al. (2014). Civic Crowdfunding Research: Challenges, Opportunities, and Future Agenda. New Media \& Society, 17(2), 249-271.

The World Bank Group. (2015). Crowdfunding in Emerging Markets: Lessons from East African Startups. Washington, DC: The World Bank Group.

Venkatesh, V., \& Davis, F. D. (2000). A Theoretical Extension of the Technology Acceptance Model: Four Longitudinal Field Studies. Management Science, 46(2), 186-204.

Wolf, C. (2017). From Harambee to Modern Crowdfunding: The Opportunities and Challenges in Sub-Saharan Africa. In D. T. Redford (Ed.), Developing Africa's Financial Services: The Importance of High-Impact Entrepreneurship. Bingley, UK: Emerald Publishing Ltd.. 
Ziegler, T., Suresh, K., Garvey, K., et al. (2018). The 2nd Annual Middle East \& Africa Alternative Finance Industry Report. Cambridge, UK: Cambridge Center for Alternative Finance.

Ziegler, T., Shneor, R., Wenzlaff, K., et al. (2019). Shifting Paradigms - The 4th European Alternative Finance Benchmarking Report. Cambridge, UK: Cambridge Centre for Alternative Finance.

Open Access This chapter is licensed under the terms of the Creative Commons Attribution 4.0 International License (http://creativecommons.org/licenses/ by/4.0/), which permits use, sharing, adaptation, distribution and reproduction in any medium or format, as long as you give appropriate credit to the original author(s) and the source, provide a link to the Creative Commons licence and indicate if changes were made.

The images or other third party material in this chapter are included in the chapter's Creative Commons licence, unless indicated otherwise in a credit line to the material. If material is not included in the chapter's Creative Commons licence and your intended use is not permitted by statutory regulation or exceeds the permitted use, you will need to obtain permission directly from the copyright holder.

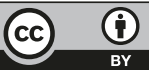

